\title{
Health and study dropout: health aspects differentially predict attrition
}

\author{
Johannes Beller* ${ }^{*}$, Siegfried Geyer and Jelena Epping
}

\begin{abstract}
Background: Participant dropout poses significant problems in longitudinal survey studies. Although it is often assumed that a participant's health predicts future study dropout, only a few studies have examined this topic, with conflicting findings. This study aims to contribute to the literature by clarifying the relationship between different aspects of health and study dropout.

Methods: The 2008 baseline sample of the German Aging Survey was used to predict study dropout $(N=4442)$. Indicators of health included physical health using the number of chronic conditions, physical functioning using the SF-36 Physical Functioning subscale, cognitive functioning using the digit symbol substitution test, and depression using the CESD-15.

Results: It was found that different aspects of health had differential associations with survey dropout: Worse physical functioning and in part worse cognitive functioning predicted increased dropout rates; contrarily, worse physical health predicted decreased dropout when controlling for other health aspects and covariates. Depression was not significantly related to study dropout.

Conclusions: Therefore, participants with chronic conditions, but minimal physical and cognitive disability were most likely to participate in the future. These findings suggest that health has a complex relationship with survey dropout and must be accounted for in longitudinal studies. Neglecting this systematic attrition due to health problems bears the risk of severely under- or overestimating health-related effects and trends.
\end{abstract}

Keywords: Health, Chronic disease, Dropout, Attrition, Longitudinal

\section{Background}

Longitudinal studies, when the same participants are observed at multiple points in time, are vital to numerous areas of science, including Medicine, Public Health, Public Opinion Research, Psychology, Sociology, Econometrics and Political Science [1]. Conducting such studies allows the analysis of change over time in phenomena of interest, which is argued to be the basis for causal inference as one of the ultimate goals of science [2]. However, how well participants can be retained over time largely determines whether these goals can be achieved

\footnotetext{
*Correspondence: beller.johannes@mh-hannover.de Hannover Medical School, Medical Sociology, Carl-Neuberg-Straße 1, 30625 Hannover, Germany
}

[3]. Participation attrition/Survey Dropout may lead to biased inferences and thus false conclusions thereby threatening the validity of longitudinal studies [4].

Although participant's health is often assumed to be one of the most important predictors of dropout, only relatively few studies have analysed this purported relationship, with mixed results [3,5-20]. For example, Banks and colleagues [5] analysed the relationship between several indicators of health, sociodemographic variables and attrition among older adults. They found that only the sociodemographic variables and not health predicted future attrition. Similarly, Wadsworth also found in their study of a national birth cohort that the response rates in general did not differ meaningfully between persons with and without serious physical 
illnesses [18]. Meneses and colleagues [8] analysed predictors of attrition among rural cancer survivors. In their study, physical health did not predict participant dropout; only mental health was found to be related to study attrition. Another study analysed predictors of attrition in Australian women [10]. In contrast to both previous studies, they found that physical health as well as mental health was significantly related to study dropout. As a last example, Goldberg and colleagues analysed predictors of attrition in a French cohort [14]. Among all of the studied predictors, physical health indicators had the strongest associations with future dropout in their study.

Therefore, although some previous studies had analyzed the relationship between health and study dropout, they provided mixed findings. Whereas some studies suggest that health does not significantly relate to survey participation, others suggest that health aspects are among the strongest predictors of study dropout. Additionally, studies from Germany are missing. So, more research is needed before firm conclusions regarding the potential contribution of health to survey dropout can be drawn [3]. As of yet, it might be speculated that worse health outcomes tend to be associated with increased dropout rates. The current study aims to examine how multiple aspects of health relate to survey dropout. It is examined which aspects of health-chronic conditions, physical functioning, depression, cognitive functioningpredict participant dropout using a large populationbased sample of German middle-aged and older adults. We ask: How do the different aspects of health relate to future study dropout?

\section{Methods}

\section{Sample}

The 2008 wave of the German Aging Survey data was used, as described in a previous study [21]. This is a cohort-sequential longitudinal, population-based study on Germans above the age of 40 years. It was provided to the main author by the Research Data Center of the German Center of Gerontology [22]. The interviews were conducted face-to-face usually in the respondent's place of residence and in the German language. National probability sampling was used for the German Aging Survey. All participants of 2008 who gave written consent were re-contacted whether they would participate in further waves of the survey in 2011, 2014, and 2017. To increase survey participation, participants were regularly contacted via information brochures and greeting cards, which were sent to the addresses of all participants. A broad range of information on the life of older adults in Germany is collected in the German Aging Survey, including their health status. In every followup data about mortality was also collected, which was based on the civil registry office and on reports of relatives of the deceased. Numerous studies have used the German Aging Survey for empirical studies on the health of middle-aged and older adults in Germany [23-28]. In this study data from all baseline participants of 2008 was used, who agreed to fill out a drop-off questionnaire, which resulted in a sample size of $N=4442$.

\section{Measures}

Several indicators of health in the 2008 wave were used to distinguish different aspects of health: number of chronic conditions, physical functioning, depression, and cognitive functioning. The number of chronic conditions was assessed via self-report with a list of conditions in a dropoff questionnaire (including heart disease, circulatory disorders, joint problems, respiratory disease, stomach or intestinal disease, cancer, diabetes, gallbladder, liver or kidney disease, bladder disease, sleep disorders, visual impairment, hearing impairment). Physical functioning was measured with the subscale Physical Functioning of the German version of the Short Form 36 Health Survey [29]. Depression was assessed with the 15-item German short version of the Center for Epidemiological Studies Depression Scale [CESD Scale; [30]]. Cognitive functioning was measured via the German version of the Digit Symbol Substitution Test derived from the Wechsler Intelligence Test [31]. Regarding marital status for married participants and for those who indicated that they lived in a long-term partnership this variable was coded as 1 and for for all other participants as 0. Education was classified according to four levels: A low educational level (coded as 1) corresponds to participants who did not complete any vocational qualification and only had up to a maximum of a graduation degree. An intermediate educational level (coded as 2) corresponds to participants with vocational qualifications or participants who had the necessary qualifications for university entrance. An upper-intermediate educational level (coded as 3) corresponds to participants with a finished upgrading training, as for example is the case in Germany for a master craftsman. Finally, a high educational level corresponds to participants with completed university studies. Additional covariates included age, income (as percentage of the population average divided by 100), network size (as the number of important persons with whom the participant has regular contact) and sex. Similar to a previous study, information on future participation of baseline participants formed the basis of our dependent variable [21]. It was coded as 0 (did not drop out / participated in at least one further wave) or 1 (dropped out / did not participate in at least one further wave). Dropout could occur for several reasons including death, inability to contact, inability to respond, and insufficient motivation. 


\section{Data analysis}

Spearman correlation and logistic regression analyses were used to examine the degree to which different aspects of health predict future participant dropout, similarly to a previous study [21]. Missing values in the 2008 wave were imputed, because participants with missing values might be more likely to also drop out in further survey waves, thus decreasing the potential for bias [32]. The MissForest algorithm was used to impute missing values. It uses nonparametric random forests which seem especially useful to imputation of mixed-type data as in the current study. The missForest algorithm is able to outperform other imputation techniques [33]. Missing values were minimal for most variables except cognitive functioning (dropout: 0\%; age: $0 \%$; sex: $0 \%$; education: $0 \%$; physical functioning: $0 \%$; network size: $0 \%$; chronic conditions: $2 \%$; depression: $2 \%$; income: $8 \%$; cognitive functioning: $21 \%$ ). To assess the robustness of our results several additional analyses were performed. Firstly, because some previous studies suggested different dropout reasons for men and women, we provide sex-stratified analyses [34]. Additionally, instead of analysing a dichotomous dropout variable, we analyse how an alternative outcome, the number of times the participants participated in further waves, is related to our health indicators. Furthermore, we analysed a non-imputed listwise deleted dataset. Lastly, since at least one study has found differences between predictors of dropout and predictors of mortality, we also conducted our analyses for a sample in which participants who are known to become deceased are excluded [5]. Thereby in the last sensitivity analysis, predictors of general survey dropout, for reasons other than mortality, are investigated.

\section{Results}

Descriptive statistics and Spearman inter-correlations are reported in Table 1. As can be seen, participants (49\% female) were on average 61.80 years old $(S D=11.88)$. $40 \%$ of participants dropped out and did not participate in successive survey waves. Indicators of health substantially and significantly correlated with each other $(0.19<=|\mathrm{r}|<=0.51)$. Descriptive differences between those who dropped out and those who continued to participate are depicted in Table 4 in Appendix.

Logistic regression results are presented in Table 2. Better physical functioning predicted decreased odds of dropout. The number of chronic conditions also significantly predicted decreased odds of dropping out and depression and cognitive functioning were not significantly related to dropout. Additionally, being older, female sex, lower levels of education, a lower income, a lower network size, and not being in a partnership predicted increased odds of dropping out. Of the health-related variables, chronic conditions and physical functioning had the largest standardized coefficients. These results were replicated when the isolated contribution of the health aspects was tested in separate regression analyses, as visible in Table 3.

Also, we conducted several additional robustness checks: First, we analyzed women and men separately (Table 5 in Appendix). Here we find that similar associations as in our main analyses, except cognitive functioning. Higher cognitive functioning predicted decreased dropout strongly in women, but also predicted a slight increase in dropout in men. Second, we analysed the participation count instead of a binary dropout variable (Table 6 in Appendix). The participation count refers to the number of future waves the participants participated in. Here we find that, similar to the main analysis, chronic conditions, physical functioning, and cognitive functioning predicted increased chances of dropout. Third, we used a non-imputed list-wise deleted dataset (Table 7 in Appendix). Again, similar results as in the main analysis were found. And fourth, we excluded participants who died during follow-up, thus testing whether cases of mortality significantly influenced our potential conclusions (Table 8 in Appendix). Here we find that, again, higher chronic conditions and higher physical functioning significantly predicted decreased chances of dropout, thus suggesting strong robustness of our results.

\section{Discussion}

Some studies had analyzed health as a predictor of study dropout but provided mixed results. Contributing to the literature by further investigating the relationship between health and study dropout, we considered four different aspects of health and investigated how these different aspects of health simultaneously predicted future study dropout in a large population-based sample. We found that the different aspects of health predicted dropout in a contrasting manner: Better physical and, in women, cognitive functioning predicted decreased odds of dropout, whereas fewer chronic conditions, and thus a better health status in terms of less chronic conditions, predicted increased chances of study dropout. Thus, participants who have chronic conditions but are not negatively impacted by them are most likely to participate in future survey waves. Depression did not show any association with dropout as soon as other health aspects were added to the model.

Our results support those studies that reported an association between health and study dropout [e.g., 10]. So, similar to some other studies we also found that health was strongly associated with survey participation [14]. At the same time, the findings of the current study contribute to the literature by showing that different aspects of health, 


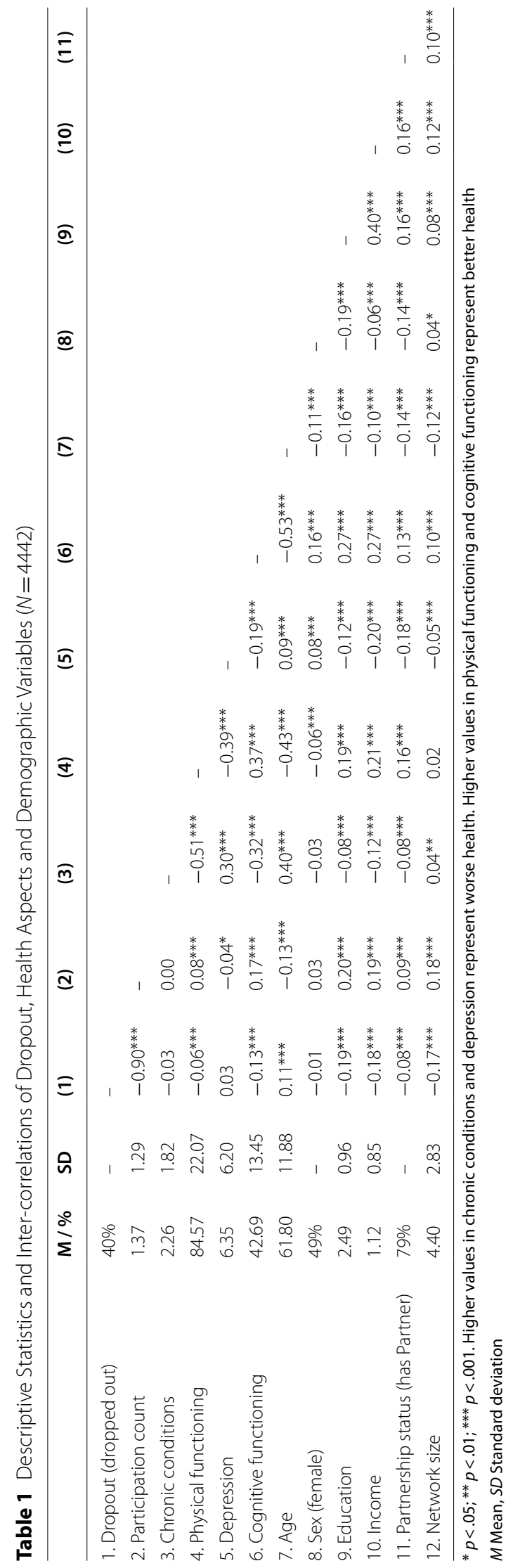


Table 2 Logistic Regression Results Predicting Study Dropout via Baseline Health and Demographic Variables $(N=4442)$

\begin{tabular}{llllll}
\hline & OR & $\mathbf{9 5 \%} \mathbf{C l}$ & $\mathbf{O R}_{\text {standardized }}$ & $\mathbf{z}$ & $\boldsymbol{p}$ \\
\hline Chronic conditions & 0.90 & {$[0.86 ; 0.94]$} & 0.82 & -5.13 & $<.001$ \\
Physical functioning & 0.99 & {$[0.99 ; 1.00]$} & 0.85 & -4.06 & $<.001$ \\
Depression & 0.99 & {$[0.98 ; 1.01]$} & 0.96 & -1.10 & .272 \\
Cognitive functioning & 1.00 & {$[0.99 ; 1.00]$} & 0.95 & -1.21 & .225 \\
Age & 1.01 & {$[1.00 ; 1.02]$} & 1.14 & 3.17 & .002 \\
Sex (female) & 0.84 & {$[0.74 ; 0.96]$} & 0.84 & -2.49 & .013 \\
Educational level & & & & & \\
$\quad$ Low (Ref.) & 1.00 & - & - & - & - \\
$\quad$ Intermediate & 0.70 & {$[0.57 ; 0.88]$} & 0.70 & -3.15 & .002 \\
$\quad$ Upper-intermediate & 0.42 & {$[0.32 ; 0.56]$} & 0.42 & -6.11 & $<.001$ \\
$\quad$ High & 0.41 & {$[0.32 ; 0.54]$} & 0.41 & -6.64 & $<.001$ \\
Income & 0.76 & {$[0.69 ; 0.86]$} & 0.79 & -4.65 & $<.001$ \\
Partnership status & 0.87 & {$[0.74 ; 1.02]$} & 0.87 & -1.73 & .084 \\
Network size & 0.90 & {$[0.88 ; 0.93]$} & 0.76 & -8.54 & $<.001$ \\
\hline
\end{tabular}

OR Unstandardized Odds Ratio, 95\%-Cl 95\% Confidence Interval of OR

$O R_{\text {standardized }}$ Standardized (z-scaled) OR, z z-Value, $p=p$-value

having chronic conditions and the impairment associated with them, might have differential associations with future survey participation. To our knowledge, this is one of the first studies to show that worse health might be associated with increased as well as decreased chances for future dropout, depending on the health aspect. This might also explain the mixed findings regarding health-related dropout reported in the literature, where, surprisingly, physical health was also sometimes found not to be related to survey participation. Global measures of health might sometimes not predict dropout because the potential dropout-increasing associations of some health outcomes and the dropout-decreasing associations of other health outcomes are conflated in this summary measure. In contrast to some previous studies, depression was also not found to predict future study dropout, after controlling for other aspects of health [e.g., 8]. In consideration of the current results, overall associations of health with study dropout might not have been consistently observed in the literature, because they only emerge strongly once the diverging associations of different sub-aspects of health are disentangled, as has been shown in this and some previous studies.

How can these differential associations be explained? The literature has identified multiple main factors that predict survey participation and dropout [35]. Among them, ability (being able to participate) and motivation (being willing to participate) have to be distinguished $[36,37]$. Likely, limitations in physical and cognitive functioning impair ones' ability to participate in surveys and are thus associated with systematic dropout. Having chronic conditions, on the other hand, was associated
Table 3 Logistic Regression Results Predicting Study Dropout via Baseline Health and Demographic Variables with Separate Analyses per Health Aspect $(N=4442)$

\begin{tabular}{|c|c|c|c|c|}
\hline & OR & $95 \%-\mathrm{Cl}$ & z & $p$ \\
\hline Chronic conditions & 0.92 & {$[0.89 ; 0.96]$} & -4.07 & $<.001$ \\
\hline \multicolumn{5}{|l|}{ Physical functioning } \\
\hline \multicolumn{5}{|l|}{ Depression } \\
\hline \multicolumn{5}{|l|}{ Cognitive functioning } \\
\hline Age & 1.01 & {$[1.01 ; 1.02]$} & 4.93 & $<.001$ \\
\hline Sex (female) & 0.84 & {$[0.74 ; 0.96]$} & -2.57 & .010 \\
\hline \multicolumn{5}{|l|}{ Educational level } \\
\hline Low (Ref.) & 1.00 & - & - & - \\
\hline Intermediate & 0.68 & {$[0.55 ; 0.84]$} & -3.56 & $<.001$ \\
\hline Upper-intermediate & 0.40 & {$[0.30 ; 0.52]$} & -6.62 & $<.001$ \\
\hline High & 0.38 & {$[0.30 ; 0.49]$} & -7.34 & $<.001$ \\
\hline Income & 0.75 & {$[0.67 ; 0.84]$} & -4.99 & $<.001$ \\
\hline Partnership status & 0.85 & {$[0.73 ; 0.99]$} & -2.03 & .043 \\
\hline \multirow[t]{2}{*}{ Network size } & 0.90 & {$[0.88 ; 0.92]$} & -8.66 & $<.001$ \\
\hline & OR & $95 \%-\mathrm{Cl}$ & z & $p$ \\
\hline \multicolumn{5}{|l|}{ Chronic conditions } \\
\hline Physical functioning & 0.99 & {$[0.99 ; 1.00]$} & -2.33 & .020 \\
\hline \multicolumn{5}{|l|}{ Depression } \\
\hline \multicolumn{5}{|l|}{ Cognitive functioning } \\
\hline Age & 1.01 & {$[1.00 ; 1.01]$} & 2.69 & .007 \\
\hline Sex (female) & 0.84 & {$[0.74 ; 0.95]$} & -2.65 & .008 \\
\hline \multicolumn{5}{|l|}{ Educational level } \\
\hline Low (Ref.) & 1.00 & - & - & - \\
\hline Intermediate & 0.70 & {$[0.57 ; 0.88]$} & -3.16 & .002 \\
\hline Upper-intermediate & 0.41 & {$[0.31 ; 0.54]$} & -6.32 & $<.001$ \\
\hline High & 0.40 & {$[0.31 ; 0.52]$} & -6.91 & $<.001$ \\
\hline Income & 0.77 & {$[0.69 ; 0.86]$} & -4.55 & $<.001$ \\
\hline Partnership status & 0.87 & {$[0.74 ; 1.02]$} & -1.71 & .088 \\
\hline \multirow[t]{2}{*}{ Network size } & 0.90 & {$[0.88 ; 0.92]$} & -8.98 & $<.001$ \\
\hline & OR & $95 \%-\mathrm{Cl}$ & z & $p$ \\
\hline
\end{tabular}

Chronic conditions

Physical functioning Depression

Cognitive functioning

Age

Sex (female)

Educational level

Low (Ref.)

Intermediate

Upper-intermediate

High

Income

Partnership status

Network size

Chronic conditions

$\begin{array}{llll}1.00 & {[0.99 ; 1.01]} & -0.67 & .504 \\ & & & \\ 1.01 & {[1.00 ; 1.02]} & 3.67 & <.001 \\ 0.84 & {[0.74 ; 0.96]} & -2.50 & .013 \\ & & & \\ 1.00 & - & - & - \\ 0.69 & {[0.56 ; 0.85]} & -3.39 & <.001 \\ 0.40 & {[0.30 ; 0.53]} & -6.56 & <.001 \\ 0.39 & {[0.30 ; 0.50]} & -7.22 & <.001 \\ 0.76 & {[0.68 ; 0.85]} & -4.79 & <.001 \\ 0.85 & {[0.73 ; 1.00]} & -2.00 & .045 \\ 0.90 & {[0.88 ; 0.92]} & -9.02 & <.001 \\ \text { OR } & 95 \%-C l & z & p\end{array}$

Physical functioning 
Table 3 (continued)

\begin{tabular}{lllll}
\hline & OR & $\mathbf{9 5 \%}-\mathbf{C l}$ & $\mathbf{z}$ & $\boldsymbol{p}$ \\
\hline Depression & & & & \\
Cognitive functioning & 1.00 & {$[0.99 ; 1.00]$} & -1.16 & .247 \\
Age & 1.01 & {$[1.00 ; 1.01]$} & 2.79 & .005 \\
Sex (female) & 0.86 & {$[0.75 ; 0.98]$} & -2.28 & .023 \\
Educational level & & & & \\
$\quad$ Low (Ref.) & 1.00 & - & - & - \\
$\quad$ Intermediate & 0.70 & {$[0.57 ; 0.87]$} & -3.18 & .001 \\
$\quad$ Upper-intermediate & 0.41 & {$[0.31 ; 0.54]$} & -6.33 & $<.001$ \\
$\quad$ High & 0.40 & {$[0.31 ; 0.52]$} & -6.86 & $<.001$ \\
Income & 0.77 & {$[0.69 ; 0.86]$} & -4.60 & $<.001$ \\
Partnership status & 0.86 & {$[0.74 ; 1.01]$} & -1.86 & .062 \\
Network size & 0.90 & {$[0.88 ; 0.92]$} & -8.98 & $<.001$ \\
\hline
\end{tabular}

OR Unstandardized Odds Ratio, 95\%-Cl 95\% Confidence Interval of OR, z z-Value, $p p$-value

with decreased odds of dropout. Having chronic conditions might increase one's need to talk about these issues and might thus increase one's willingness to participate in studies that address these topics. The lack of an association of depression with dropout in this study might be explained by the fact that depression represents a prevalent co-morbidity of physical morbidity [38]. In line with this hypothesis, depression was associated with dropout in the univariate analysis, but the association disappeared once one controlled for other aspects of health and demographic background information. However, future studies should disentangle the observed associations between aspects of health and study dropout even further, for example by distinguishing different sub-constructs of depression and emotional states.

The interpretation of longitudinal studies should be considered in light of these results. In contrast to previous work, strong associations of health with dropout were found. For example, one increase in a standard deviation of chronic conditions was associated with $18 \%$ decreased odds of dropping out, and each increase in a standard deviation of physical functioning was associated with $15 \%$ reduced odds of dropout. Therefore, participants seem to selectively participate in the further survey waves depending on their health. Biases in longitudinal studies might thus result in accordance to the degree that health is related to the phenomena of interest. For example, in longitudinal studies participants could seem functionally healthier than they are, all the while seeming to suffer from more chronic conditions and multimorbidity, although these biases might not extend to mental health [e.g., [39-42]]. Thus, authors of substantive research should be attentive to the potential health-bias inherent to longitudinal research.

Research employing longitudinal methods needs to account for this potential bias. One often-suggested strategy is to impute missing data [43]. Importantly, for this strategy to be feasible, multiple indicators of health need to be included that are able to account for the differential associations of health aspects with dropout. At least, indicators of chronic disease status and functional health need to be considered. Including only one overall health variable cannot account for the observed differential health-dependent dropout. Another strategy to perform longitudinal analyses and avoid this bias is to use other data sources that do not suffer from selective health dropout, like claims or health insurance data, which however might also be susceptible to other biases [44-46].

The current study could be improved in multiple ways. First, different types of dropout were not differentiated in the study, which might be needed to validate the supposed mechanisms. Similarly, due to the correlational nature of the research, causation cannot be ascertained. Although the current study statistically controlled for a range of potential covariates, there is still a risk of residual confounding. As such, future studies are needed that include an even more diverse set of variables in their analyses. Secondly, although the study used a large population-based sample of middle-aged and older adults, the sample did not include young adults. The associations of different aspects of health with attrition might differ in younger adults from middle-aged and older adults and should thus be analyzed by future studies. We also only included baseline health variables. Future studies might include time-varying health variables in a more complicated research design to study how dynamics of health development predict future dropout. In a similar vein, although several different health aspects were considered there could still be residual confounding. Therefore, future studies are needed that include further variables as potential predictors of study dropout. Furthermore, future studies should study whether similar results can be obtained when different study designs are used, such as is the case in RCTs or with different survey topics [e.g., [35, $47,48]$. Lastly, it seems unclear why cognitive functioning seemed to predict dropout differentially in men and women, which should be investigated by future studies.

\section{Conclusion}

The current study provides further evidence on how different indicators of health predict survey dropout. Participants with chronic conditions, but minimal physical and cognitive disability are most likely to participate in followup studies. Health has thus a complex relationship with survey dropout and must be accounted for in longitudinal studies to provide accurate research results. Neglecting this systematic attrition due to health problems bears the risk of severely under- or overestimating health-related effects and trends. 


\section{Appendix: Robustness analyses}

Table 4 Descriptive Differences between Participants who Dropped out and those who continued to Participate in the Study $(N=4442)$

\begin{tabular}{|c|c|c|c|c|}
\hline & \multicolumn{4}{|c|}{ Stratified by Dropout } \\
\hline & Level & Participated & Dropped Out & $p$ \\
\hline N & & 2651 & 1791 & \\
\hline Chronic Conditions (M (SD)) & & $2.28(1.74)$ & $2.24(1.92)$ & .486 \\
\hline Physical Functioning (M (SD)) & & $86.52(19.52)$ & $81.68(25.11)$ & $<.001$ \\
\hline Depression (M (SD)) & & $6.15(5.88)$ & $6.65(6.64)$ & .008 \\
\hline Cognitive Functioning (M (SD)) & & $43.96(12.92)$ & $40.82(14.00)$ & $<.001$ \\
\hline Age (M (SD)) & & $60.76(11.26)$ & $63.35(12.58)$ & $<.001$ \\
\hline \multirow[t]{2}{*}{$\operatorname{Sex}(\%)$} & Male & 51.0 & 52.2 & .434 \\
\hline & Female & 49.0 & 47.8 & \\
\hline \multirow[t]{4}{*}{ Education (\%) } & Low & 7.4 & 14.1 & $<.001$ \\
\hline & Intermediate & 50.1 & 60.4 & \\
\hline & Upper-Intermediate & 14.3 & 9.6 & \\
\hline & High & 28.2 & 15.9 & \\
\hline Income (M (SD)) & & $121.36(92.99)$ & $99.93(68.87)$ & $<.001$ \\
\hline \multirow[t]{2}{*}{ Partnership Status (\%) } & Not in a Partnership & 18.0 & 24.5 & $<.001$ \\
\hline & In a Partnership & 82.0 & 75.5 & \\
\hline Network Size (M (SD)) & & $4.78(2.81)$ & $3.83(2.76)$ & $<.001$ \\
\hline
\end{tabular}


Table 5 Logistic Regression Results Predicting Study Dropout via Baseline Health and Demographic Variables $(N=4442)$ in Men and Women

\begin{tabular}{|c|c|c|c|c|c|}
\hline & \multicolumn{5}{|c|}{ Men } \\
\hline & $\mathrm{OR}$ & $95 \%-\mathrm{Cl}$ & $\mathrm{OR}_{\text {standardized }}$ & z & $p$ \\
\hline Chronic conditions & 0.90 & {$[0.86 ; 0.96]$} & 0.84 & -3.29 & .001 \\
\hline Physical functioning & 0.99 & {$[0.99 ; 1.00]$} & 0.84 & -3.27 & .001 \\
\hline Depression & 1.01 & {$[0.99 ; 1.02]$} & 1.03 & 0.62 & .537 \\
\hline Cognitive functioning & 1.01 & {$[1.00 ; 1.02]$} & 1.15 & 2.68 & .007 \\
\hline Age & 1.01 & {$[1.00 ; 1.02]$} & 1.16 & 2.79 & .005 \\
\hline \multicolumn{6}{|l|}{ Educational level } \\
\hline Low (Ref.) & 1.00 & - & - & - & - \\
\hline Intermediate & 0.67 & {$[0.44 ; 1.02]$} & 0.67 & -1.86 & .063 \\
\hline Upper-intermediate & 0.42 & {$[0.26 ; 0.68]$} & 0.42 & -3.57 & $<.001$ \\
\hline High & 0.37 & {$[0.24 ; 0.59]$} & 0.37 & -4.23 & $<.001$ \\
\hline Income & 0.73 & {$[0.63 ; 0.85]$} & 0.73 & -4.04 & $<.001$ \\
\hline Partnership status & 0.89 & {$[0.69 ; 1.13]$} & 0.89 & -0.97 & .333 \\
\hline \multirow[t]{3}{*}{ Network Size } & 0.92 & {$[0.89 ; 0.95]$} & 0.92 & -5.10 & $<.001$ \\
\hline & \multicolumn{5}{|c|}{ Women } \\
\hline & $\mathrm{OR}$ & $95 \%-\mathrm{Cl}$ & $\mathrm{OR}_{\text {standardized }}$ & z & $p$ \\
\hline Chronic conditions & 0.89 & {$[0.83 ; 0.94]$} & 0.80 & -3.94 & $<.001$ \\
\hline Physical functioning & 0.99 & {$[0.99 ; 1.00]$} & 0.88 & -2.28 & .023 \\
\hline Depression & 0.98 & {$[0.97 ; 1.00]$} & 0.90 & -1.98 & .048 \\
\hline Cognitive functioning & 0.98 & {$[0.97 ; 0.99]$} & 0.79 & -4.19 & $<.001$ \\
\hline Age & 1.01 & {$[1.00 ; 1.02]$} & 1.11 & 1.71 & .086 \\
\hline \multicolumn{6}{|l|}{ Educational level } \\
\hline Low (Ref.) & 1.00 & - & - & - & - \\
\hline Intermediate & 0.76 & {$[0.58 ; 0.98]$} & 0.76 & -2.09 & .037 \\
\hline Upper-intermediate & 0.41 & {$[0.28 ; 0.61]$} & 0.41 & -4.54 & $<.001$ \\
\hline High & 0.45 & {$[0.32 ; 0.65]$} & 0.45 & -4.40 & $<.001$ \\
\hline Income & 0.79 & {$[0.67 ; 0.94]$} & 0.79 & -2.71 & .007 \\
\hline Partnership status & 0.87 & {$[0.70 ; 1.08]$} & 0.87 & -1.25 & .211 \\
\hline Network Size & 0.89 & {$[0.86 ; 0.92]$} & 0.89 & -6.74 & $<.001$ \\
\hline
\end{tabular}

$O R$ Unstandardized Odds Ratio, 95\%-Cl 95\% Confidence Interval of OR

$O R_{\text {standardized }}$ Standardized (z-scaled) OR, z z-Value, $p p$-value
Table 6 Ordinal Regression Results predicting Participation Count in Further Waves $(N=4442)$

\begin{tabular}{llllll}
\hline & OR & $\mathbf{9 5 \% - C l}$ & $\mathbf{O R}_{\text {standardized }}$ & $\mathbf{z}$ & $\boldsymbol{p}$ \\
\hline Chronic conditions & 1.08 & {$[1.05 ; 1.12]$} & 1.16 & 4.35 & $<.001$ \\
Physical functioning & 1.01 & {$[1.01 ; 1.01]$} & 1.20 & 4.98 & $<.001$ \\
Depression & 1.01 & {$[1.00 ; 1.01]$} & 1.03 & 1.01 & .313 \\
Cognitive functioning & 1.01 & {$[1.00 ; 1.01]$} & 1.09 & 2.38 & .018 \\
Age & 0.99 & {$[0.99 ; 1.00]$} & 0.91 & -2.55 & .011 \\
Sex (female) & 1.23 & {$[1.09 ; 1.38]$} & 1.23 & 3.40 & .001 \\
Educational level & - & - & - & - & - \\
$\quad$ Low (Ref.) & 1.00 & - & - & - & - \\
$\quad$ Intermediate & 1.53 & {$[1.25 ; 1.87]$} & 1.53 & 4.15 & $<.001$ \\
$\quad$ Upper-intermediate & 2.34 & {$[1.83 ; 2.99]$} & 2.34 & 6.80 & $<.001$ \\
High & 2.45 & {$[1.94 ; 3.09]$} & 2.45 & 7.56 & $<.001$ \\
Income & 1.19 & {$[1.10 ; 1.29]$} & 1.16 & 4.19 & $<.001$ \\
Partnership status & 1.19 & {$[1.03 ; 1.37]$} & 1.19 & 2.39 & .017 \\
Network size & 1.09 & {$[1.07 ; 1.12]$} & 1.29 & 8.83 & $<.001$ \\
\hline
\end{tabular}

OR Unstandardized Odds Ratio, 95\%-Cl 95\% Confidence Interval of OR,

$O R_{\text {standardized }}$ Standardized (z-scaled) OR, zz-Value, $p p$-value. Participation was measured as the number of future waves in which the baseline population was participating (0 to 3 ). The participation count refers to the number of future waves the participants participated in

Table 7 Logistic Regression Results Predicting Study Dropout via Baseline Health and Demographic Variables in a Listwise Deleted Dataset $(N=3155)$

\begin{tabular}{llllll}
\hline & OR & $\mathbf{9 5 \%} \mathbf{C} \mathbf{C l}$ & $\mathbf{O R}_{\text {standardized }}$ & $\mathbf{z}$ & $\boldsymbol{p}$ \\
\hline Chronic conditions & 0.90 & {$[0.85 ; 0.94]$} & 0.81 & -4.35 & $<.001$ \\
Physical functioning & 0.99 & {$[0.99 ; 1.00]$} & 0.88 & -2.65 & .008 \\
Depression & 0.99 & {$[0.98 ; 1.01]$} & 0.96 & -0.93 & .351 \\
Cognitive functioning & 1.00 & {$[0.99 ; 1.00]$} & 0.94 & -1.27 & .204 \\
Age & 1.01 & {$[1.00 ; 1.02]$} & 1.11 & 2.13 & .033 \\
Sex (female) & 0.87 & {$[0.74 ; 1.02]$} & 0.87 & -1.67 & .096 \\
Educational level & - & - & - & - & - \\
$\quad$ Low (Ref.) & 1.00 & - & - & - & - \\
$\quad$ Intermediate & 0.68 & {$[0.52 ; 0.88]$} & 0.68 & -2.87 & .004 \\
$\quad$ Upper-intermediate & 0.40 & {$[0.29 ; 0.56]$} & 0.40 & -5.29 & $<.001$ \\
$\quad$ High & 0.40 & {$[0.29 ; 0.55]$} & 0.40 & -5.67 & $<.001$ \\
Income & 0.81 & {$[0.71 ; 0.92]$} & 0.84 & -3.23 & .001 \\
Partnership status & 0.82 & {$[0.68 ; 0.99]$} & 0.82 & -2.02 & .043 \\
Network size & 0.90 & {$[0.88 ; 0.93]$} & 0.74 & -7.41 & $<.001$ \\
\hline
\end{tabular}

OR Unstandardized Odds Ratio, 95\%-C/ 95\% Confidence Interval of OR,

$O R_{\text {standardized }}$ Standardized (z-scaled) OR, z z-Value, $p p$-value 
Table 8 Logistic Regression Results Predicting Study Dropout via Baseline Health and Demographic Variables Excluding Participants Who Died during Follow up $(N=3967)$

\begin{tabular}{llllll}
\hline & OR & $\mathbf{9 5 \%}-\mathbf{C l}$ & OR $_{\text {standardized }}$ & $\mathbf{z}$ & $\boldsymbol{p}$ \\
\hline Chronic conditions & 0.90 & {$[0.86 ; 0.94]$} & 0.83 & -4.69 & $<.001$ \\
Physical functioning & 0.99 & {$[0.99 ; 1.00]$} & 0.87 & -3.31 & $<.001$ \\
Depression & 0.99 & {$[0.98 ; 1.01]$} & 0.97 & -0.81 & .416 \\
Cognitive functioning & 1.00 & {$[0.99 ; 1.00]$} & 0.96 & -1.00 & .319 \\
Age & 1.01 & {$[1.00 ; 1.02]$} & 1.15 & 3.35 & $<.001$ \\
Sex (female) & 0.84 & {$[0.73 ; 0.97]$} & 0.84 & -2.43 & .015 \\
Educational level & - & - & - & - & - \\
$\quad$ Low (Ref.) & 1.00 & - & - & - & - \\
$\quad$ Intermediate & 0.67 & {$[0.53 ; 0.85]$} & 0.67 & -3.31 & $<.001$ \\
$\quad$ Upper-intermediate & 0.40 & {$[0.30 ; 0.54]$} & 0.40 & -6.06 & $<.001$ \\
$\quad$ High & 0.37 & {$[0.28 ; 0.49]$} & 0.37 & -7.03 & $<.001$ \\
Income & 0.76 & {$[0.67 ; 0.86]$} & 0.79 & -4.51 & $<.001$ \\
Partnership status & 0.88 & {$[0.74 ; 1.04]$} & 0.88 & -1.53 & .127 \\
Network size & 0.90 & {$[0.88 ; 0.92]$} & 0.74 & -8.43 & $<.001$
\end{tabular}

OR Unstandardized Odds Ratio, 95\%-Cl 95\% Confidence Interval of OR,

$O R_{\text {standardized }}$ Standardized (z-scaled) OR, z z-Value, $p$ p-value

\section{Abbreviations}

CESD: Center for Epidemiological Studies Depression Scale; OR: Odds Ratio; Cl: Confidence Interval.

\section{Acknowledgements}

Not applicable.

\section{Authors' contributions}

JB conceived of the idea, performed the analyses, interpreted the results, and wrote the manuscript. JE and SG have made substantial contributions to the conception of the study and the interpretation of the results and have provided critical feedback. All authors have read and approved the final manuscript.

\section{Funding}

Open Access funding enabled and organized by Projekt DEAL. This paper was funded by the DFG (German Research Foundation), reference number GE $1167 / 15-1$. The funding body had no role in the design of the study and collection, analysis, and interpretation of data and writing of the manuscript.

\section{Availability of data and materials}

The datasets supporting the conclusions of this article are available in the repository of the German Centre of Gerontology, https://www.dza.de/en/ research/fdz/german-ageing-survey/data. However, restrictions apply to the availability of these data, which were used under license for the current study, and so are not publicly available.

\section{Declarations}

\section{Ethics approval and consent to participate}

Ethics board approval was not required for the current study, because only secondary data analysis of the completely anonymized data was conducted, and ethical approval is not mandatory for general surveys in Germany when anonymized data are analyzed. The permanent advisory board to the German Ageing Survey concluded that the German Ageing Survey study also did not need approval from an ethics committee because it did not meet the criteria for requiring an ethical statement (risk for the respondents, lack of information about the aims of the study, examination of patients). This rationale is supported by the German Research Foundation-guidelines available at https://www.dfg.de/en/research_funding/faq/faq_humanities_social_scien ce/index.html. The German Ageing Survey meets the ethical standards delineated in the 1964 Declaration of Helsinki and its amendments. Prior to the interview, written informed consent was given by all participants of the study. The permanent advisory board of the German Centre of Gerontology, however, approved of the sampling method, the consent to participate and the instruments used in the study, which were also in line with national regulations.

\section{Consent for publication \\ Not applicable.}

\section{Competing interests}

The authors declare that they have no competing interests.

Received: 18 November 2021 Accepted: 11 January 2022

Published online: 30 January 2022

\section{References}

1. de Leeuw ED, Lugtig P. Dropouts in Longitudinal Surveys. In: Balakrishnan $\mathrm{N}$, Colton T, Everitt B, Piegorsch W, Ruggeri F, Teugels JL, editors. Wiley StatsRef: Statistics Reference Online. Chichester: John Wiley \& Sons, Ltd; 2015. p. 1-6.

2. Shadish WR, Cook TD, Campbell DT. Experimental and quasi-experimental designs for generalized causal inference. Belmont: Wadsworth, Cengage Learning; 2002.

3. Chatfield MD, Brayne CE, Matthews FE. A systematic literature review of attrition between waves in longitudinal studies in the elderly shows a consistent pattern of dropout between differing studies. J Clin Epidemiol. 2005;58:13-9.

4. Bell ML, Kenward MG, Fairclough DL, Horton NJ. Differential dropout and bias in randomised controlled trials: when it matters and when it may not. BMJ. 2013;346:e8668.

5. Banks J, Muriel A, Smith J. Attrition and health in ageing studies: evidence from ELSA and HRS. Long Life Course Stud. 2011;2:101-26.

6. Byles JE, Rahman MM, Princehorn EM, Holliday EG, Leigh L, Loxton D, et al. Successful ageing from old to very old: a longitudinal study of 12,432 women from Australia. Age Ageing. 2019;48:803-10.

7. Cooney TM, Schaie KW, Willis SL. The relationship between prior functioning on cognitive and personality dimensions and subject attrition in longitudinal research. J Gerontol. 1988;43:P12-7.

8. Meneses K, Azuero A, Su X, Benz R, McNees P. Predictors of attrition among rural breast cancer survivors: predictors of cancer survivor attrition. Res Nurs Health. 2014;37:21-31.

9. Ramsey I, de Rooij BH, Mols F, Corsini N, Horevoorts NJE, Eckert M, et al. Cancer survivors who fully participate in the PROFILES registry have better health-related quality of life than those who drop out. J Cancer Surviv. 2019;13:829-39.

10. Young AF, Powers JR, Bell SL. Attrition in longitudinal studies: who do you lose? Aust N Z J Public Health. 2006;30:353-61.

11. Zethof D, Nagelhout GE, de Rooij M, Driezen P, Fong GT, van den Putte $B$, et al. Attrition analysed in five waves of a longitudinal yearly survey of smokers: findings from the ITC Netherlands survey. Eur J Pub Health. 2016;26:693-9.

12. de Graaf R, Bijl RV, Smit F, Ravelli A, Vollebergh WAM. Psychiatric and sociodemographic predictors of attrition in a longitudinal study the Netherlands mental health survey and incidence study (NEMESIS). Am J Epidemiol. 2000;152:1039-47.

13. Deeg DJH, van Tilburg T, Smit JH, de Leeuw ED. Attrition in the longitudinal aging study Amsterdam. J Clin Epidemiol. 2002;55:319-28.

14. Goldberg M, Chastang JF, Zins M, Niedhammer I, Leclerc A. Health problems were the strongest predictors of attrition during follow-up of the GAZEL cohort. J Clin Epidemiol. 2006;59:1213-21.

15. Medical Research Council Cognitive Function and Ageing Study (MRC (FAS), Matthews FE, Chatfield M, Brayne C. An investigation of whether factors associated with short-term attrition change or persist over ten years: data from the Medical Research Council Cognitive Function and Ageing Study (MRC CFAS). BMC Public Health. 2006;6:185. 
16. Nishiwaki Y, Clark H, Morton SM, Leon DA. Early life factors, childhood cognition and postal questionnaire response rate in middle age: the Aberdeen children of the 1950sstudy. BMC Med Res Methodol. 2005;5:16.

17. Slymen DJ, Drew JA, Elder JP, Williams SJ. Determinants of non-compliance and attrition in the elderly. Int J Epidemiol. 1996;25:411-9.

18. Wadsworth ME, Mann SL, Rodgers B, Kuh DJ, Hilder WS, Yusuf EJ. Loss and representativeness in a 43 year follow up of a national birth cohort. J Epidemiol Community Health. 1992;46:300-4.

19. Wadsworth MEJ, Butterworth SL, Hardy RJ, Kuh DJ, Richards M, Langenberg C, et al. The life course prospective design: an example of benefits and problems associated with study longevity. Soc Sci Med. 2003;57:2193-205.

20. Wadsworth M, Kuh D, Richards M, Hardy R. Cohort profile: the 1946 National Birth Cohort (MRC National Survey of health and development). Int J Epidemiol. 2006;35:49-54

21. Beller J, Geyer S. Personal values strongly predict study dropout. Surv Res Methods. 2021;15:269-80.

22. Klaus D, Engstler H, Mahne K, Wolff JK, Simonson J, Wurm S, et al. Cohort Profile: the GERMAN Ageing Survey (DEAS). Int J Epidemiol. 2017; 46:1105-1105g.

23. Hajek A, De Bock F, Wieler LH, Sprengholz P, Kretzler B, König H-H. Perceptions of health care use in Germany during the COVID-19 pandemic. Int J Environ Res Public Health. 2020;17:9351.

24. Siedlecki KL, Yazdani N, Minahan J, Falzarano F. Examining processing speed as a predictor of subjective well-being across age and time in the German aging survey. Aging Neuropsychol Cognit. 2020;27:66-82.

25. Boeder J, Tse DCK. Measuring self-perceptions of aging: differences between measures when predicting health outcomes. J Gerontol Series B. 2021;76:825-35.

26. Beller J. Personal values and mortality: power, benevolence and selfdirection predict mortality risk. Psychol Health. 2021;36:115-27.

27. Beller J, Wagner A. Disentangling loneliness: differential effects of subjective loneliness, network quality, network size, and living alone on physical, mental, and cognitive health. J Aging Health. 2018;30:521-39.

28. Beller J, Wagner A. Loneliness, social isolation, their synergistic interaction, and mortality. Health Psychol. 2018;37:808-13.

29. Bullinger M, Kirchberger I, Ware J. Der deutsche SF-36 Health Survey Übersetzung und psychometrische Testung eines krankheitsübergreifenden Instruments zur Erfassung der gesundheitsbezogenen Lebensqualität. J Public Health. 1995;3:21-36.

30. Radloff LS. The CES-D scale: a self-report depression scale for research in the general population. Appl Psychol Meas. 1977;1:385-401.

31. Hoyer WJ, Stawski RS, Wasylyshyn C, Verhaeghen P. Adult age and digit symbol substitution performance: a Meta-analysis. Psychol Aging. 2004;19:211-4.

32. Yan T, Curtin R. The relation between unit nonresponse and item nonresponse: a response continuum perspective. Int J Public Opin Res. 2010;22:535-51.

33. Stekhoven DJ, Buhlmann P. MissForest--non-parametric missing value imputation for mixed-type data. Bioinformatics. 2012;28:112-8.

34. Ross MW, Daneback K, Månsson S, Tikkanen R, Cooper A. Characteristics of men and women who complete or exit from an on-line internet sexuality questionnaire: a study of instrument dropout biases. J Sex Res. 2003;40:396-402.

35. Groves RM, Cialdini RB, Couper MP. Understanding the decision to participate in a survey. Public Opin Q. 1992;56:475.

36. de Leeuw ED. Dropouts in longitudinal data. In: Everitt BS, Howell DC, editors. Encyclopedia of statistics in behavioral science. Chichester: John Wiley \& Sons, Ltd; 2005.

37. Tinker A, Mein G, Bhamra S, Ashcroft R, Seale C. Retaining older people in longitudinal research studies: some ethical issues. Res Ethics. 2009;5:71-4.

38. Kang H-J, Kim S-Y, Bae K-Y, Kim S-W, Shin I-S, Yoon J-S, et al. Comorbidity of depression with physical disorders: research and clinical implications. Chonnam Med J. 2015:51:8.

39. Verropoulou G, Tsimbos C. Disability trends among older adults in ten European countries over 2004-2013, using various indicators and survey of health, ageing and retirement in Europe (SHARE) data. Ageing Soc. 2017:37:2152-82

40. Beller J, Miething A, Regidor E, Lostao L, Epping J, Geyer S. Trends in grip strength: age, period, and cohort effects on grip strength in older adults from Germany, Sweden, and Spain. SSM - Popul Health. 2019;9:100456.
41. Beller J, Regidor E, Lostao L, Miething A, Kröger C, Safieddine B, et al. Decline of depressive symptoms in Europe: differential trends across the lifespan. Soc Psychiatry Psychiatr Epidemiol. 2020. https://doi.org/10. 1007/s00127-020-01979-6.

42. Beller J, Epping J. Disability trends in Europe by age-period-cohort analysis: Increasing disability in younger cohorts. Disabil Health J. 2020:100948.

43. Asendorpf JB, van de Schoot R, Denissen JJA, Hutteman R. Reducing bias due to systematic attrition in longitudinal studies: the benefits of multiple imputation. Int J Behav Dev. 2014;38:453-60.

44. Beller J, Bauersachs J, Schäfer A, Schwettmann L, Heier M, Peters A, et al. Diverging trends in age at first myocardial infarction: evidence from two German population-based studies. Sci Rep. 2020;10:9610.

45. Safieddine B, Sperlich S, Beller J, Lange K, Epping J, Tetzlaff J, et al. Socioeconomic inequalities in type 2 diabetes in employed individuals, nonworking spouses and pensioners. SSM - Popul Health. 2020;11:100596.

46. Epping J, Geyer S, Tetzlaff J. The effects of different lookback periods on the sociodemographic structure of the study population and on the estimation of incidence rates: analyses with German claims data. BMC Med Res Methodol. 2020;20:229.

47. Lynn P. Longer interviews may not affect subsequent survey participation propensity. Public Opin Q. 2014;78:500-9.

48. Lynn P. Tackling panel attrition. In: Vannette DL, Krosnick JA, editors. The Palgrave handbook of survey research. Cham: Springer International Publishing; 2018. p. 143-53.

\section{Publisher's Note}

Springer Nature remains neutral with regard to jurisdictional claims in published maps and institutional affiliations.

Ready to submit your research? Choose BMC and benefit from

- fast, convenient online submission

- thorough peer review by experienced researchers in your field

- rapid publication on acceptance

- support for research data, including large and complex data types

- gold Open Access which fosters wider collaboration and increased citations

- maximum visibility for your research: over 100M website views per year

At BMC, research is always in progress.

Learn more biomedcentral.com/submissions 